\section{Extramitochondrial OPA1 and adrenocortical function}

\author{
6 Q1 László Fülöp ${ }^{\mathrm{a}}$, Anikó Rajki ${ }^{\mathrm{b}}$, Dávid Katona ${ }^{\mathrm{a}}$, Gergö Szanda ${ }^{\mathrm{a}}$, András Spät ${ }^{\mathrm{a}, *}$ \\ $7 \quad{ }^{a}$ Department of Physiology, Faculty of Medicine, Semmelweis University, Hungary \\ 8 b Laboratory of Molecular Physiology, Hungarian Academy of Sciences, POB 259, H-1444 Budapest, Hungary
}

9

\begin{abstract}
A B S T R A C T
We have previously described that silencing of the mitochondrial protein OPA1 enhances mitochondrial $\mathrm{Ca}^{2+}$ signaling and aldosterone production in H295R adrenocortical cells. Since extramitochondrial OPA1 (emOPA1) was reported to facilitate cAMP-induced lipolysis, we hypothesized that emOPA1, via the enhanced hydrolysis of cholesterol esters, augments aldosterone production in H295R cells. A few OPA1 immunopositive spots were detected in $\sim 40 \%$ of the cells. In cell fractionation studies OPA1/COX IV (mitochondrial marker) ratio in the post-mitochondrial fractions was an order of magnitude higher than that in the mitochondrial fraction. The ratio of long to short OPA1 isoforms was lower in post-mitochondrial than in mitochondrial fractions. Knockdown of OPA1 failed to reduce db-cAMP-induced phosphorylation of hormone-sensitive lipase (HSL), $\mathrm{Ca}^{2+}$ signaling and aldosterone secretion. In conclusion, OPA1 could be detected in the post-mitochondrial fractions, nevertheless, OPA1 did not interfere with the CAMP - PKA - HSL mediated activation of aldosterone secretion.
\end{abstract}

(c) 2013 Published by Elsevier Ireland Ltd.

\section{Introduction}

The precursor of corticosteroids is cholesterol. Cholesterol may be synthetized within the endoplasmic reticulum or taken up from plasma lipoproteins. Cholesterol esters, taken up by endocytosis of receptor-bound LDL particles, are hydrolyzed in the endoplasmic reticulum. More important for steroid biosynthesis is HDL-transported esterified cholesterol, taken up by scavenger receptor B1 (Rone et al., 2009) and hydrolyzed by cholesterol esterase (Rodrigueza et al., 1999). The esterase was recently found to be identical with the HSL of lipocytes (Kraemer et al., 2004). Following reesterification cholesterol accumulates in special, phospholipid layer bounded droplets. Rapid increase of cortisol secretion during stress or increased aldosterone secretion during acute fluid loss requires the rapid mobilization of cholesterol stored in these lipid droplets (Hattangady et al., 2011; Vinson et al., 1992). Deesterification is performed again by HSL (Kraemer et al., 2004).

Abbreviations: $\left[\mathrm{Ca}^{2+}\right]_{\mathrm{m}}$, mitochondrial $\mathrm{Ca}^{2+}$ concentration; AKAP, A-kinase anchoring protein; CaMKII, $\mathrm{Ca}^{2+} /$ calmodulin-dependent kinase II; COX IV, cytochrome $c$ oxidase IV; db-cAMP, dibutiryl-cAMP; emOPA1, extramitochondrial OPA1; HSL, hormone-sensitive lipase; IMM, inner mitochondrial membrane; IMS, mitochondrial intermembrane space; Mfn 1, mitofusin 1; OMM, outer mitochondrial membrane; OPA1, Optic Atrophy 1; PDI, protein disulfide isomerase; PKA, protein kinase A; Plin, perilipin; StAR, Steroidogenic Acute Regulating Protein; TSPO, (mitochondrial) Translocation Protein (previously peripheral benzodiazepine receptor).

Q2 * Corresponding author. Tel.: +36 1 4591500; fax: +36 12667480.

E-mail address: spat@eok.sote.hu (A. Spät).
The dual action of HSL is under hormonal control. ACTH, through CAMP-PKA, phosphorylates and thus activates the enzyme (Hirsch and Rosen, 1984; Holm et al., 2000; Kraemer et al., 2004; Trzeciak and Boyd, 1974) and also induces its expression (Granneman and Moore, 2008; Holysz et al., 2011). Calcium ion, the second messenger of angiotensin II, acts via CaMKII to activate (Cherradi et al., 1998) and through p42/p44 mitogen-activated protein kinase (Cherradi et al., 2003) to increase the expression of HSL.

Transfer of the released cholesterol to the side-chain cleaving

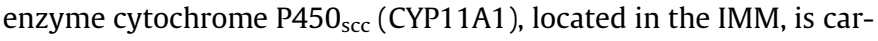
ried out by a complex of cytosolic and mitochondrial proteins (Rone et al., 2009). At least two components of this complex, StAR and the translocator protein TSPO (previously named as peripheral benzodiazepine receptor) are phosphorylated and induced by PKA (Dyson et al., 2008; Fleury et al., 2004; Manna et al., 2002; Midzak et al., 2011). Although $\mathrm{Ca}^{2+}$ - mobilizing agonists (through $\mathrm{Ca}^{2+}$ and protein kinase C) were also reported to phosphorylate StAR (Betancourt-Calle et al., 2001; Cherradi et al., 1998) their major effect is the induction of StAR expression (Clark et al., 1995; Lucki et al., 2012; Martin et al., 2008).

In adipocytes activated PKA phosphorylates and brings about translocation of the cytosolic HSL to the membrane fraction (Hirsch and Rosen, 1984). This translocation requires the 62-kDa protein perilipin 1 (Plin 1) located on the surface of lipid droplets (Greenberg et al., 1991; Miyoshi et al., 2006). It is assumed that non-phosphorylated Plin 1 inhibits the access of phosphorylated HSL to its substrate (Brasaemle et al., 2009; Sztalryd et al., 2003; Tansey

0303-7207/\$ - see front matter (c) 2013 Published by Elsevier Ireland Ltd. http://dx.doi.org/10.1016/j.mce.2013.07.021 
et al., 2001; Zhang et al., 2003). Albeit PKA-mediated phosphorylation of Plin is not required for the translocation, phosphorylation is essential for hormone-induced lipolysis (Miyoshi et al., 2006). It is assumed that phosphorylation of Plin 1 permits the activation of adipocyte triglyceride lipase (Granneman et al., 2011; Subramanian et al., 2004; Yamaguchi et al., 2007) which provides diacylglycerol for further hydrolysis by HSL (Zimmermann et al., 2004).

A recently described factor participating in hormonally-induced lipolysis is Optic Atrophy 1 (OPA1). OPA1 (and its ortholog Mgm1p in yeast) has been known as a dynamin-related mitochondrial GTPase protein. In cooperation with Mitofusin 1 (Mfn 1) OPA1 induces mitochondrial fusion and its mutation is the most common cause of type 1 autosomal dominant optic atrophy (Belenguer and Pellegrini, 2012; Cipolat et al., 2004). Unexpectedly, OPA1 has been detected in lipocytes on the surface of Plin-coated lipid droplets (Pidoux et al., 2011). Immunocytochemical and immunoprecipitation studies showed that PKA binds to the Plin-associated OPA1 and the formation of this complex results in Plin phosphorylation and lipolysis. OPA1 contains an A-kinase binding domain and thus it may function as an AKAP. In fractionation studies the amount of OPA1 in the lipid droplet fraction far exceeded that in the mitochondrial fraction. Based on these observations a significant role has been attributed to OPA1 in the hormonal control of lipolysis, assuming that OPA1 potentiates the phosphorylation of Plin 1 by PKA and thus makes further steps possible (presumably the activation of adipocyte triglyceride lipase) (Greenberg et al., 2011; Pidoux et al., 2011). We are not aware of studies on emOPA1 in cell types other than adipocyte.

In humans OPA 1 has eight mRNA isoforms and the expressed proteins can be separated in five bands between 96 and $84 \mathrm{kDa}$ in Western blots. The two higher-molecular mass bands, the socalled long isoforms are mixture of isoforms 1, 2, 4 and 7 whereas the three short isoforms contain proteolytic products of the long ones and also isoforms 3, 5, 6 and 8. The long isoforms are attached to the IMM, the soluble short ones were found in the IMS partly associated to the OMM (Delettre et al., 2000; Lenaers et al., 2009; Liesa et al., 2009). OPA1 controls the diameter of the junction of cristae (Scorrano et al., 2002) and thus modifies the molecular diffusion between the lumen of the cristae and the IMS (Frey et al., 2002) and/or between the boundary (inner) and crista membrane (Sukhorukov and Bereiter-Hahn, 2009). Knockdown of OPA1 in
H295R human adrenocortical cells, probably due to the altered diffusion conditions, facilitates the transfer of cytosolic $\mathrm{Ca}^{2+}$ signal into the mitochondrial matrix (Fülöp et al., 2011) resulting in enhanced aldosterone production (Spät et al., 2012).

In addition to HSL another factor participating in lipolysis, Plin1a (formerly Plin A) has also been detected in Y-1 murine adrenocortical cells (Servetnick et al., 1995). Other Plin isoforms, predominantly Plin1c (formerly Plin C), could also be detected following incubation with cholesterol (Hsieh et al., 2012). Importantly, Plin1a was phosphorylated in a cAMP-dependent manner (Servetnick et al., 1995). The data showing that identical molecules participate in the control of lipid metabolism in adipocytes and adrenocortical cells prompted us to examine whether OPA1, functioning as an AKAP, is a feasible candidate for regulating cAMP-induced steroid secretion. The verified and hypothetical mechanisms supplying cholesterol to mitochondria are shown in Fig. 1. We presumed that silencing of OPA1, if functioning as an AKAP in the extramitochondrial space, would reduce PKA-mediated steroid production to a greater extent than PKA-independent response. Our observations indicate that OPA1 is present in the extramitochondrial compartment in H295R cells but the role of emOPA1 in the control of steroid secretion could not be demonstrated.

\section{Materials and methods}

\subsection{Materials}

NIH-H295R cells (ATCC, CRL-2128) were purchased from LGC Standards Gmbh, Wesel, Germany. siRNA and silencing RNA products as well as OPTI-MEM, Lipofectamine 2000, Fluo-4 and MitoTracker Deep Red were purchased from Life Technologies (Paisley, UK).

CholEsteryl-BODIPY FL $\mathrm{C}_{12}$ (C-3927MP) was from Life Technologies (San Diego, CA, USA), UltroSer G was from Bio Sepra (Cergy-Saint-Christophe, France). 2mt-eGFP (eGFP fused with a doublet of human cytochrome $c$ oxidase target sequence) was a gift from Dr. B. Enyedi (Budapest, Hungary). Coat-A-Count RIA kit was purchased from Siemens Health Care Diagnostics (Los Angeles, CA).

Primary antibodies were purchased as follows: anti-OPA1 monoclonal antibody (612606): BD Bioscience (Franklin Lakes,

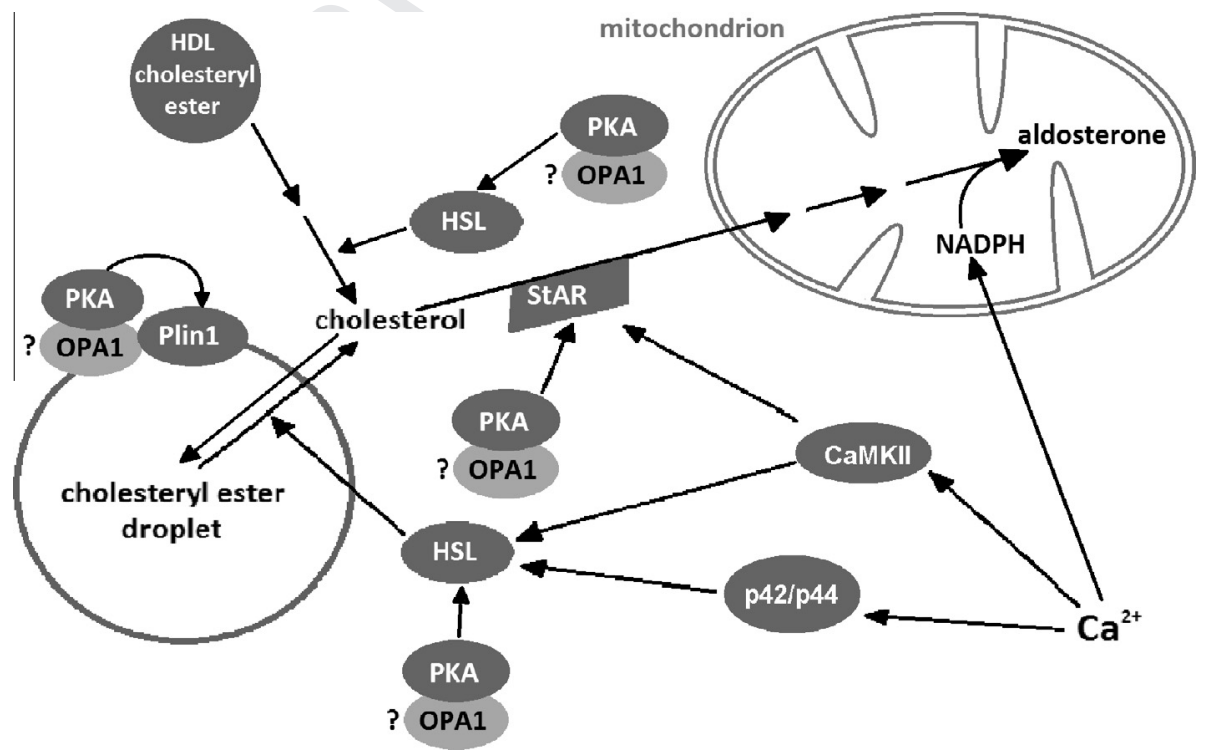

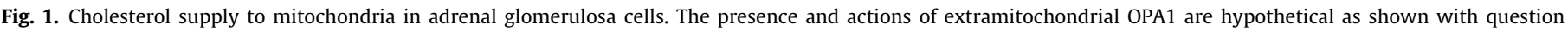
marks. 
NJ); anti-cytochrome oxidase IV (COX IV) monoclonal antibody (SC-58348) and polyclonal antibody (D-20; SC-693599, anti-cytochrome $c$ rabbit polyclonal antibody (SC-7159) and HSL monoclonal antibody (sc-74489): Santa Cruz Biotechnology (Santa Cruz, CA); anti-protein disulfide isomerase monoclonal antibody (ab2792): Abcam (Cambridge, UK); anti-MFN1 mouse polyclonal antibody (H00055669-M04): Abnova (Taipei, Taiwan) and antiphospho-HSL rabbit polyclonal antibody (PA5-17488): Thermo Scientific (Rockford, IL). Secondary antibodies were as follows: for Western blots: anti-mouse immunoglobulin-HRP: GE Healthcare (Amersham, UK), anti-rabbit immunoglobulin-HRP: GE Health Care Diagnostic (Deerfield, IL) and donkey anti-goat IgG-HRP: Santa Cruz Biotechnology; for immunocytochemistry: Alexa Fluor 568 goat anti-mouse IgG (A 11004) and Alexa Fluor 633 goat anti-rabbit IgG (A 21070): Life Technologies.

\subsection{Cell culture and transfection}

H295R cells were grown in DMEM/Ham's F12 (1:1 v/v) containing $1 \% \mathrm{ITS}^{+}, 2 \%$ UltroSer $\mathrm{G}, 100 \mathrm{U} / \mathrm{ml}$ penicillin and $100 \mu \mathrm{g} / \mathrm{ml}$ streptomycin. Passage numbers 4-20 were used. For transfection with 2mt-eGFP (for confocal microscopic examination) we used $0.4 \mu \mathrm{g}$ plasmid DNA with $0.4 \mu \mathrm{l}$ Lipofectamine 2000 in $220 \mu \mathrm{l}$ OPTIMEM medium. The transfection was performed on day 2 and repeated on day 3. The cells were fixed one day later. For transfection with scrambled RNA or siRNA (for the examination of HSL phosphorylation and in aldosterone experiments) the cells were electroporated before plating, using the Neon electroporator and kit (MPK10025) of Life Technologies. For measuring aldosterone production the cells were stimulated with appropriate agonists on day 4 (2-h stimulation) or on days 3 and 4 (24-h stimulation). For confocal measurement of $\left[\mathrm{Ca}^{2+}\right]$ the cells were transfected with siRNA on day 2, applying RNAiMax.

\subsection{Immunocytochemistry}

For immunocytochemistry about $5 \times 10^{4}$ cells were plated onto glass coverslips. Staining with $2 \mu \mathrm{M}$ CholEsteryl-BODIPY FL $\mathrm{C}_{12}$ for one day was carried out at $37^{\circ} \mathrm{C}$ in $\mathrm{CO}_{2}$ incubator. The cells were fixed in $4 \%$ paraformaldehyde (in PBS, $\mathrm{pH} 7.4$ ) for $10 \mathrm{~min}$ at room temperature and then rinsed. For quenching autofluorescence the samples were incubated in $100 \mathrm{mM}$ glycine for $45 \mathrm{~min}$ and then washed twice. Permeabilisation was performed with a mixture of $5 \%$ milk powder, $0.2 \%$ Triton $\mathrm{X}-100$, at room temperature for 15 min. Blocking with 5\% milk powder, $1 \%$ FCS and $0.1 \%$ Triton X100 lasted for $1 \mathrm{~h}$. Incubation with primary antibodies (1:50) in blocking buffer at $4{ }^{\circ} \mathrm{C}$ lasted overnight. The secondary antibody (usually at a dilution of 1:100, but for cytochrome $c$ staining Alexa Fluor 633 was diluted 500-fold) was applied in blocking buffer after repeated washings. Further six washings were followed by mounting with MOWIOL.

Microscopic examination was undertaken with a Zeiss LSM710 confocal laser scanning microscope, operated with ZEN 9.0 software. The cells were examined with a $63 \times / 1.4$ oil immersion objective (Plan-Apochromat, Zeiss). As an exception, for cells transfected with 2 mt-eGFP a $40 \times / 1.2$ water immersion objective (CApochromat, Zeiss) was used. Imaging was performed in multitrack mode. The optical slice was $1 \mu \mathrm{m}$. The measured cross-over of Alexa 568 into the emission range of Alexa 633 has been subtracted applying Image J $1.43 \mathrm{u}$ software. The imaging parameters are shown in Supplementary Table 1. Images were deconvoluted with Image J plug-in “Iterative Deconvolve 3D” (Version 5.2). Additional lambda scan imaging was performed with simultaneously acquired emission spectrum of each fluorophore, using array detector.

\subsection{Cell fractionation}

\subsubsection{Homogenization and mitochondrial fractions}

Cell fractionation was carried out with three separate subclones, first with $3 \times 10^{7}$ and then with $10^{8}$ cells. Three days after passage the cells were homogenized using microscopic control. A combination of about 40 strokes in a glass-Teflon Potter-Elvijem homogenizer and 40 aspirations and ejections through a 26 guage needle were applied in a homogenization buffer ( $50 \mu \mathrm{l} / 10^{6}$ cells) (containing 250 sucrose mM, 10 mM Tris. $\mathrm{HCl}$ (pH 7.4), 1 mM EDTA, $10 \mathrm{mM}$ NaF, $1 \mathrm{mM}$ benzamidine, $0.075 \mathrm{U} / \mathrm{ml}$ Aprotinin, $1 \mathrm{mM}$ PMSF and 1:100 Sigma Mammalian Protease Inhibitor Cocktail) completed with an equal volume of distilled water (total $=1$ volume). Following the homogenization the buffer was made isosmotic with the addition of 0.4 volume of a 2.25 -fold concentrated homogenization buffer. The homogenate was centrifuged in a swing-out rotor at $1000 g_{\max }$ for $10 \mathrm{~min}$. The nuclear pellet was discarded; the supernatant was centrifuged in an Eppendorf fuge $\left(12,000 g_{\max }\right)$ for $15 \mathrm{~min}$. To obtain mitochondrial fraction the pellets were pooled, twice resuspended and recentrifuged in homogenation buffer. The resulting pellet was shaken for $30 \mathrm{~min}$ at $37^{\circ} \mathrm{C}$ in an extracting solution (Servetnick et al., 1995) and finally spun in the Eppendorf fuge for $15 \mathrm{~min}$. The supernatant, sampled for protein determination, was completed with sample buffer (see below) and stored at $-20^{\circ} \mathrm{C}$ for analysis on Western blot.

\subsubsection{Cytosolic fraction}

The pooled supernatants obtained after the first centrifugation in Eppendorf fuge were transferred into ultracentrifuge tubes and centrifuged in a fixed-angle rotor at $31,000 \mathrm{~g}_{\max }$ for $25 \mathrm{~min}$. No pellet was obtained, a sample from the middle height of the tube was withdrawn for protein determination and another aliquot was completed with sample buffer and stored at $-20{ }^{\circ} \mathrm{C}$ for analysis on Western blot.

\subsubsection{Fat cake fraction}

A cloudy aggregate floating in the uppermost layer of the cytosolic fraction and hence termed fat cake, was aspirated and extracted with $2 \mathrm{vol}$ of extracting solution and processed as done for mitochondria (see above). Samples were withdrawn from the lower phase for protein and Western blot analysis as described for the mitochondrial fraction. Since COX IV concentration of these samples could not be reliably measured, those measured in the cytosolic fraction were used in the calculation of OPA1/COX IV ratio. The sample buffer applied for the different cell fractions contained the following components, yielding a final concentration given in brackets: Tris. $\mathrm{HCl}$ ( $\sim 40 \mathrm{mM})$, glycerol (10\%), $\beta$-mercaptoethanol (5\%), bromophenolblue (0.005\%) and SDS (2\%) (pH 7.0).

All the above steps, with exceptions as specified, were performed at $4{ }^{\circ} \mathrm{C}$.

\subsection{Electrophoresis and immunoblotting}

The cells were suspended in ice-cold lysis buffer $(100 \mathrm{mM} \mathrm{NaCl}$, $30 \mathrm{mM}$ HEPES pH 7.4, 0.2\% Triton X-100, $20 \mathrm{mM} \mathrm{NaF}, 2.5 \mathrm{mM} \mathrm{Na}-$ EGTA, $2.5 \mathrm{mM}$ Na-EDTA, $10 \mathrm{mM}$ benzamidine, $0.075 \mathrm{U} / \mathrm{ml}$ Aprotinin, 1:100 Sigma Mammalian Protease Inhibitor Cocktail, 1 mM sodium-vanadate, $10 \mathrm{mM}$ PMSF). The insoluble fraction was removed with centrifugation. The supernatant was completed with sample buffer to give a final concentration as described above (Section 2.4).

Lysed cell samples as well as samples of subcellular fractions were run on $10 \%$ (but for HSL 8\%) SDS-PAGE and transferred onto nitrocellulose membrane (pore size: $0.45 \mu \mathrm{m}$ ). After blocking, the primary antibodies were applied as follows: cytochrome $c$ (1:200), COX IV (1:200), HSL (1:1000), phospho-HSL (1:500), 
Mfn1 (1:500), OPA1 (1:500), PDI (1:3000). Anti-mouse and antirabbit secondary antibodies were applied at a dilution of 1:5000 and $1: 2500$, respectively. For quantitative estimation of OPA1 and COX IV a dilution series of the mitochondrial samples were run parallel with samples of the two supramitochondrial fractions. For quantitative estimation of OPA1 and COX IV a dilution series of the mitochondrial samples were run parallel with samples of the two supramitochondrial fractions. Cytosolic and fat cake samples were compared with mitochondrial samples of comparable optical density on the radiograms. Integral density of regions of interest (ROIs), measured with Image J $1.43 \mathrm{u}$, was corrected for background. The resulting value was regarded as indicator of the amount of separated protein.

\subsection{Aldosterone production}

For aldosterone experiments the cells were transfected by means of electroporation on day 1 using either equal amounts of three siRNA preparations for OPA1 (HSS107431, 107432 and 107433) or siRNA for Mfn1 (5141600) or a 1:1 mixture of nonsilencing RNA species with appropriate GC content (12935400 and 129305200). Following electroporation about $2.5 \times 10^{5}$ transfected cells per sample were plated on a 24 -well culture dish. The cells were incubated in the tissue culture medium until the 2nd (for 24-h stimulation) or 3rd day (for 2-h stimulation) when the medium was replaced with $0.1 \%$ UltroSer G. Next day a 1 -h preincubation in serum-free medium was followed by a 2 -h or $24-\mathrm{h}$ incubation in the serum-free medium, in the presence of appropriate drugs. Aldosterone content of the incubation medium was measured with Coat-A-Count RIA kit, for calibration synthetic aldosterone was dissolved in cell-free incubation medium.

\subsection{Measurement of cytosolic $\mathrm{Ca}^{2+}$ concentration}

Cells transfected with Mfn1 or OPA1 siRNA were examined for $\left[\mathrm{Ca}^{2+}\right]_{\mathrm{c}}$ three days after transfection. Fluorescence of cells preloaded with Fluo 4 and MitoTracker Deep Red was monitored at room temperature in multitrack mode with Zeiss LSM710 confocal laser scanning microscope, operated with ZEN 11.0 software. The cells were examined with a $63 \times / 1.4$ oil immersion objective (Plan-Apochromat, Zeiss). Transfection was regarded successful if mitochondria showed fragmented pattern.

\subsection{Protein determination}

Protein content of cell samples was estimated with Bradford assay for aldosterone measurements and with BCA assay before SDSPAGE separations.

\subsection{Statistics}

Means + SEM are shown. For estimating significance of differences unpaired $t$-test, factorial ANOVA and Tukey HSD test (Statistica 11) were used.

\section{Results}

\subsection{Location of OPA1 in H295R cells}

The intracellular location of OPA1 was first examined in cells transfected with mitochondrially targeted eGFP (2mt-eGFP). As shown in Fig. 2, mitochondria were immunopositive for OPA1 and a few OPA1 spots could be found also out of the eGFP-labeled
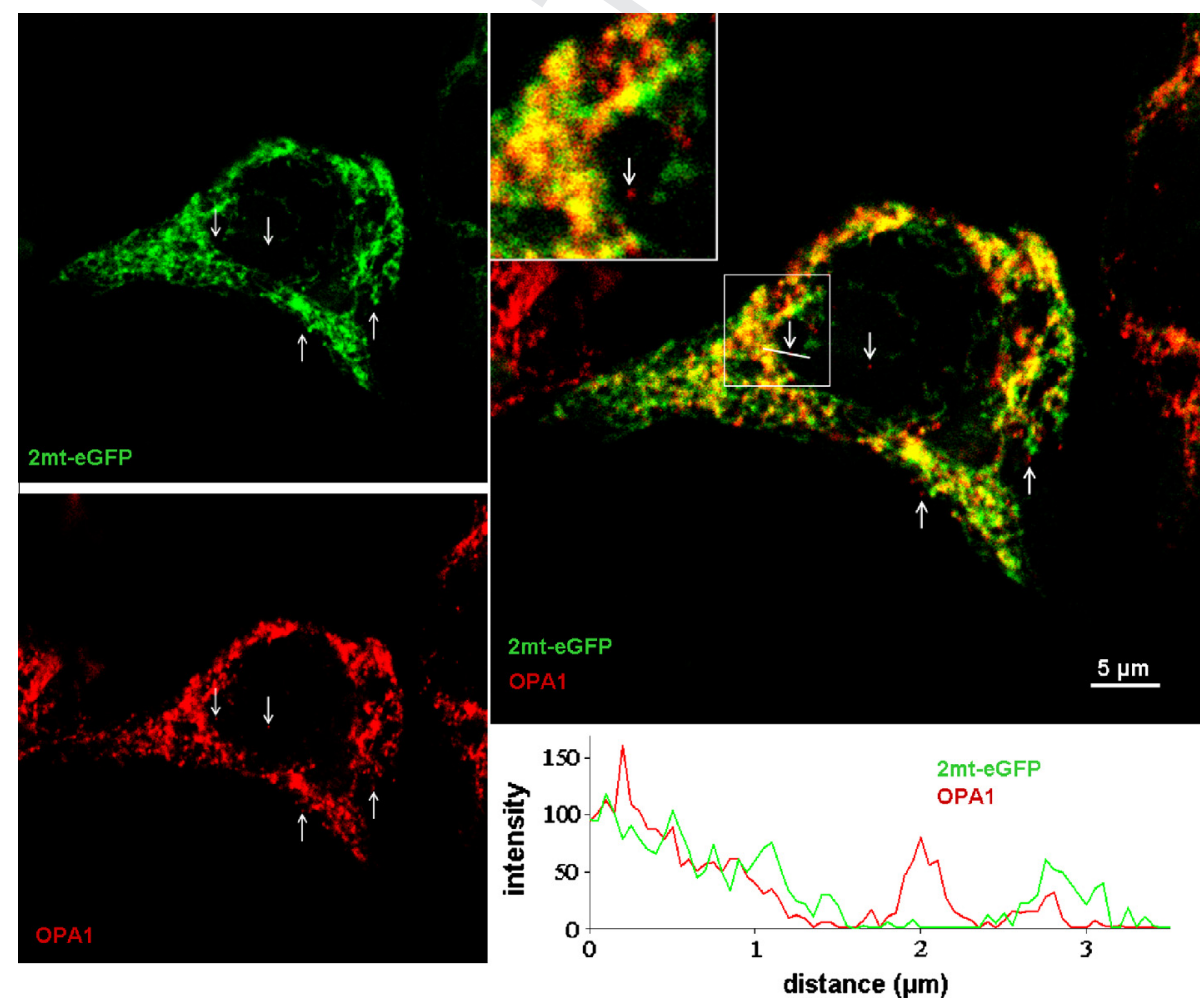

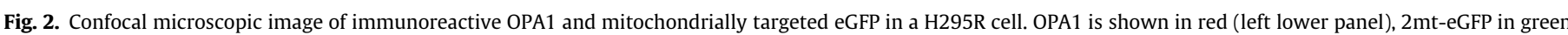

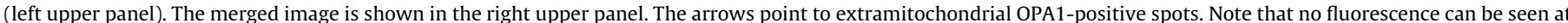

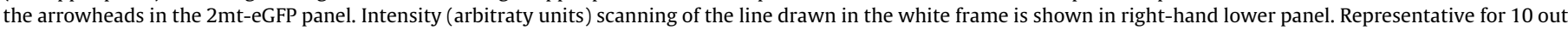
of 21 cells. (For interpretation of the references to colour in this figure legend, the reader is referred to the web version of this article.) 

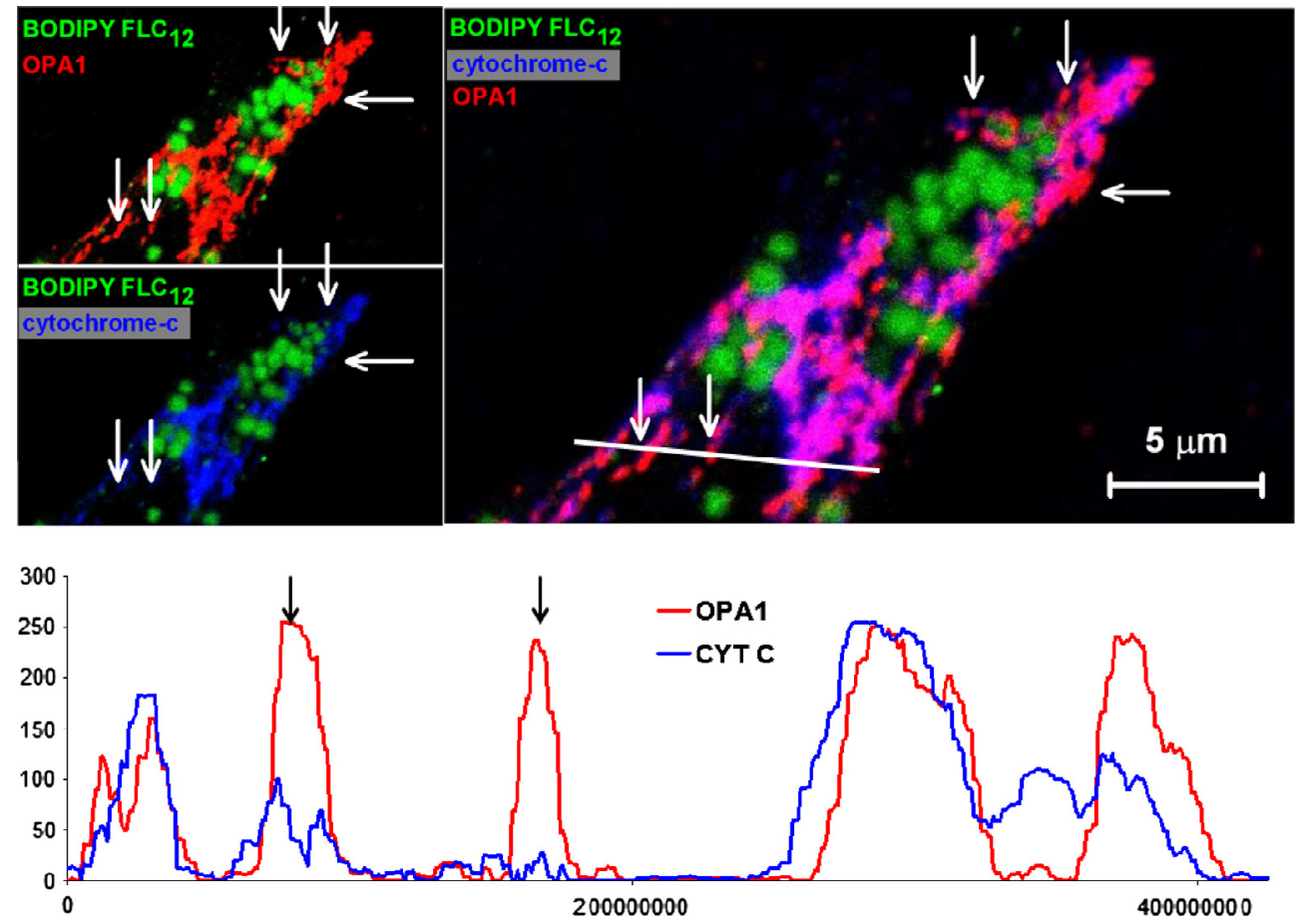

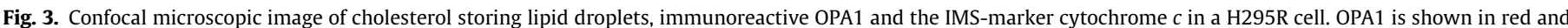

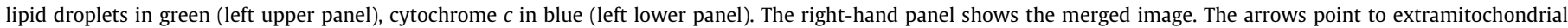

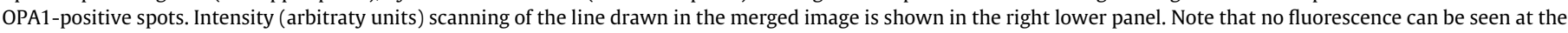

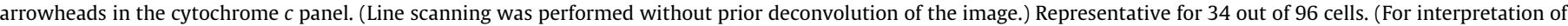
the references to colour in this figure legend, the reader is referred to the web version of this article.)

particles. Altogether, emOPA1 could be detected in 10 out of 21 cells. In order to localize the presumed emOPA1 more precisely, we applied triple staining. Cholesterol storing lipid droplets were stained with the fluorescent cholesterol-ester mimetic CholEsteryl-BODIPY $\mathrm{FL} \mathrm{C}_{12}$, OPA1 was immunostained and IMS was labeled with cytochrome $c$ antibody. In average two emOPA1 immunopositive spots have been detected in 34 cells. These spots were mostly located in the vicinity of lipid droplets although OPA1 immunopositivity around the droplets predominantly colocalized with mitochondria (Fig. 3). emOPA1 could not be detected in another 62 cells. No OPA1 immunoreactivity was found after omitting the primary antibody (not shown). Examination with lambda scan mode of confocal microscopy also revealed extramitochondrial immunopositive spots for OPA1 (Supplementary Fig. 1).

\subsection{OPA1 in subcellular fractions}

The homogenized cells were separated into three fractions by differential centrifugation. Mitochondria were pelleted at 12,000 $g_{\max } \times 15 \mathrm{~min}$. To obtain cytosol the supernatant was centifuged

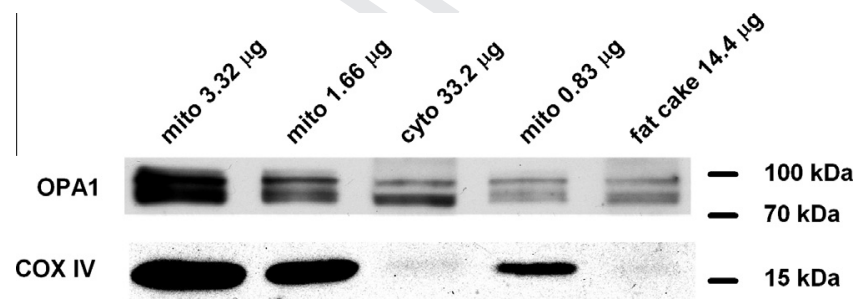

Fig. 4. Western blot analysis of cell fractions. H295R cells were fractionated as detailed in Section 2.4. OPA1 and the IMM-marker COX IV are shown. Representative for 3 cell fractionation studies. at $31,000 g_{\max } \times 25 \mathrm{~min}$. A cloudy aggregate floating in the uppermost layer of the cytosolic fraction was withdrawn and termed (in analogy to fat cells) fat cake (Greenberg et al., 1991). The mitochondrial, cytosolic and fat cake fractions were analyzed for OPA1 and the IMM-marker COX IV by Western blotting.

All three fractions contained OPA1 as well as COX IV (Fig. 4 and Supplementary Table 2). In order to estimate mitochondrial contamination, the ratio of OPA1 to COX IV was estimated for all three fractions, taking this ratio in the mitochondrial fraction as unit. The ratio increased in the cytosol over mitochondria by a factor of $11.5 \pm 3.5$ units $(n=3)$. Due to insufficient amount of protein in one experiment the ratio in the fat cake could be estimated only in two fractionation studies where it attained 26.5 and 33.5 units. These data indicate that the amount of OPA1 in the extramitochondrial fractions was more than attributable to mitochondrial contamination (Supplementary Table 2).

The balance of the long (L) and short (S) isoforms of OPA1 in the cytosolic fraction was shifted towards the short ones as compared to that in the mitochondrial fraction. Whereas the $S$ isoforms may have originated from the IMS of mitochondria with damaged OMM, L isoforms, which are anchored to the IMM (Delettre et al., 2000; Lenaers et al., 2009; Liesa et al., 2009), may not have such an origin. The contamination of the post-mitochondrial fractions with cytochrome $c$ (Supplementary Table 2) supports the assumption that $\mathrm{S}$ isoforms may originate from damaged mitochondria.

\subsection{Effect of OPA1 silencing on HSL phosphorylation}

In order to test the presumed AKAP function of OPA1 we examined the knock-down of OPA1 on phosphorylation of HSL, a major target of PKA. Exposing the cells to db-cAMP for $2 \mathrm{~h}$ brought about a concentration dependent increase in the phosphorylated fraction of the enzyme $(p=0.0009)$. Although the mean extent of phosphorylation was somewhat lower in cells transfected with OPA1 siRNA 

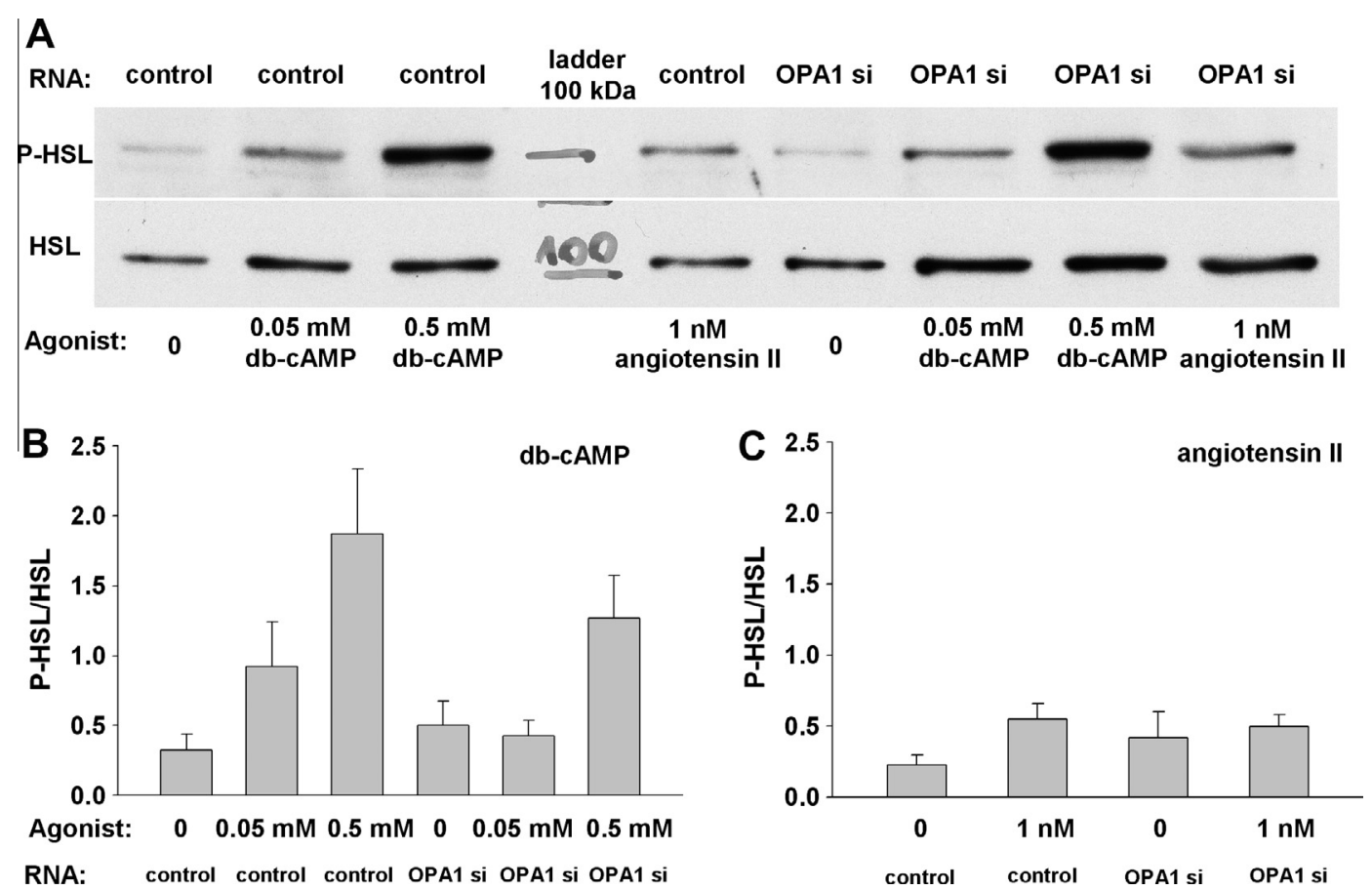

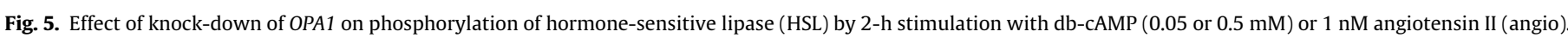

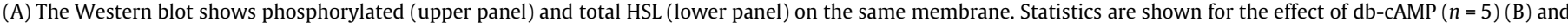
angiotensin II $(n=4)(C)$. The ordinates show the quotients of phosphorylated and total HSL densities. The effect of OPA1 siRNA was not significant (ANOVA, $p=0.19)$.

Fig. 5 and Supplementary Fig. 2), the effect of silencing was not statistically significant $(p=0.19)$.

Next we examined whether angiotensin II-induced phosphorylation of HSL was dependent on OPA1. The hormone ( $1 \mathrm{nM})$ doubled the formation of phospho-HSL. The knock-down of OPA1 was without effect (Fig. 5).

\subsection{Effect of OPA1 silencing on CAMP-induced $\mathrm{Ca}^{2+}$ signaling}

Eighty-five Mfn1-silenced cells and 52 OPA1-silenced cells were stimulated with $0.05 \mathrm{mM}$ db-cAMP. Most of the cells failed to respond within $10 \mathrm{~min}$. The evaluable response in 7 control cells was almost thrice as high as that in 3 OPA1 - silenced cells; however, the number of responsive cells was too low for obtaining any conclusion. When the cells were stimulated with $0.5 \mathrm{mM}$ db-cAMP, exhibited characteristic $\mathrm{Ca}^{2+}$ signal, with a lag-time between 4 and $10 \mathrm{~min}$. Silencing failed to modify the amplitude of $\mathrm{Ca}^{2+}$ peaks (Supplementary Fig. 3).

\subsection{Effect of OPA1 silencing on aldosterone production}

In order to ascertain whether emOPA1 exerts any effect on cholesterol supply of steroid production we examined the effect of OPA1 silencing on the PKA-dependent aldosterone production. Considering that siRNA for OPA1 induces fragmentation of mitochondria (Olichon et al., 2003) and the consecutive changes in mitochondrial volume/surface ratio might influence signaling processes, comparison with maintained OPA1 expression but fragmented mitochondria were also required. Knock-down of Mfn1 also induces fragmentation without changes in the structure of IMM (Arnoult et al., 2005; Eura et al., 2003). Transfection with siRNA for OPA1 in H295R cells efficiently reduced the expression of OPA1 protein and did not influence that of Mfn1 protein (Fig. 1 in Fülöp et al., 2011) whereas transfection with siRNA for Mfn1 exerted reciprocal effect (not shown). Knock-down of OPA1 and Mfn1 8 out of $42 \mathrm{Mfn} 1$-silenced cells and 9 out of 39 OPA1-silenced cells induce fragmentation with indistinguishable morphometric changes (Figs. S1 and S3 in Fülöp et al., 2011) therefore, in addition to the effect of transfection with scrambled RNA the effect of siRNA against Mfn1 on hormone production has also been examined.

Aldosterone production has been studied under two different conditions. During acute (2-h) stimulation with db-cAMP or angiotensin II hormone production depends on the activation of the mechanism transporting cholesterol to the IMM. In contrast, during long-term stimulation several proteins participating in hormone production are also synthesized (Coulombe et al., 1996; Hattangady et al., 2011; Spät and Hunyady, 2004). The greatly enhanced steroid production will then be much more dependent on available free cholesterol.

Aldosterone response to db-cAMP or angiotensin II was examined in cells transfected with either control RNA or Mfn1 siRNA or OPA1 siRNA. Each group was stimulated with either 0.05 or $0.5 \mathrm{mM}$ db-cAMP or $1 \mathrm{nM}$ angiotensin II for $2 \mathrm{~h}$ or with $0.5 \mathrm{mM}$ db-cAMP or $10 \mathrm{nM}$ angiotensin II for $24 \mathrm{~h}$. Qualitatively similar aldosterone responses were measured in the short and long-term stimulation series. db-cAMP stimulated aldosterone production in each group in a concentration-dependent way. Comparison of aldosterone production rates after transfection with various RNA species showed that highest responses were attained in the OPA1-silenced cells (for the effect of OPA1 siRNA: $p=10^{-4}$ ) (Fig. 6 and 7). Importantly, knock-down of OPA1 equally affected the response to db-cAMP and angiotensin II, related to the effect of either type of control transfection (Table 1). These measurements indicate that the effect of OPA1 siRNA does not depend on the involvement of PKA in the stimulation of aldosterone production.

\section{Discussion}

Mitochondrial protein OPA1 located in close proximity with the lipid droplets has recently been described in lipocytes (Pidoux et al., 2011). Functioning as an AKAP it amplifies the PKA-induced phosphorylation of Plin 1, thus permitting enhanced lipolytic ac- 


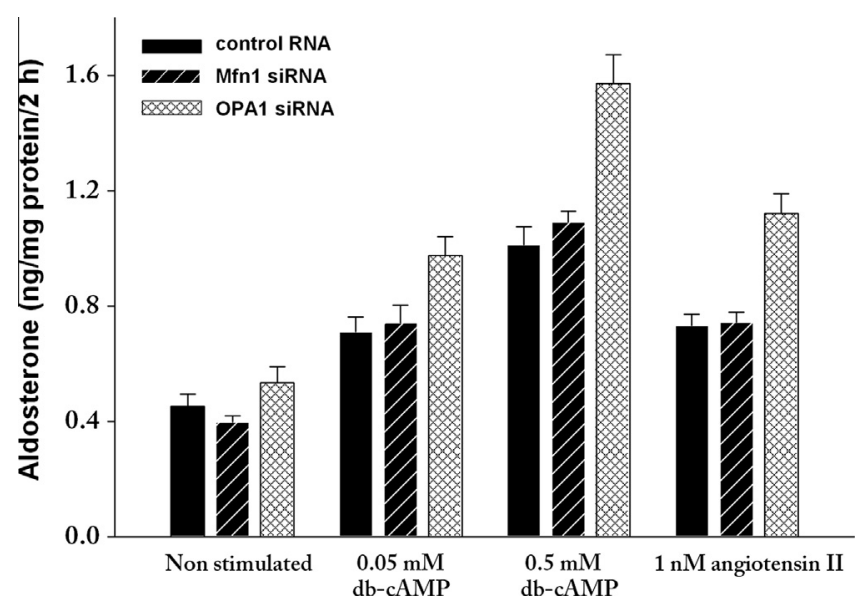

Fig. 6. Effect of knock-down of OPA1 on short-term aldosterone production. The cells were transfected by means of electroporation with scrambled RNA or siRNA against OPA1 or Mfn1 before plating. (Knock-down of Mfn1 evokes mitochondrial fragmentation similar to the effect of siRNA for OPA1.) Three days later the cells were stimulated with db-cAMP $(0.05$ or $0.5 \mathrm{mM})$ or angiotensin II $(1 \mathrm{nM})$ for $2 \mathrm{~h}$. Mean + SEM of 6 experiments derived from 3 separate cell passages are shown. The effect of agonists and that of RNA were highly significant (ANOVA, $p \ll 10^{-6}$ ). Highest aldosterone responses were attained in the OPA1-silenced cells (Tukey test, $\left.p=10^{-4}\right)$.

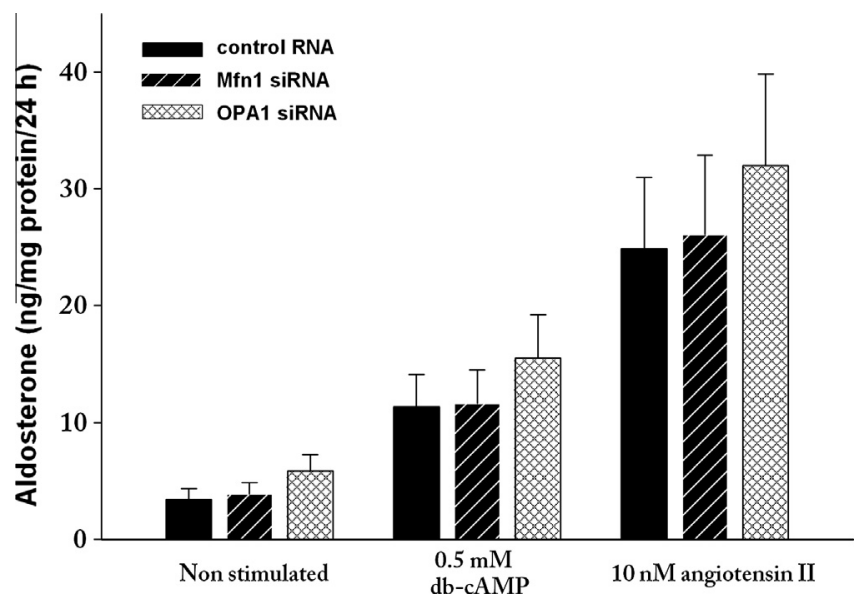

Fig. 7. Effect of knock-down of OPA1 on long-term aldosterone production. The cells were transfected as described for Fig. 6, however, two days after plating the cells were stimulated with db-cAMP $(0.5 \mathrm{mM})$ or angiotensin II $(10 \mathrm{nM})$ for $24 \mathrm{~h}$. Mean + SEM of 6 experiments derived from 4 separate cell passages are shown. The effect of agonists and that of RNA were highly significant (ANOVA, $p \ll 10^{-6}$ ). Highest aldosterone responses were attained in the OPA1-silenced cells (Tukey test, $\left.p=10^{-4}\right)$. hypothetised that also in adrenocortical cells, under control conditions, Plin 1 forms a barrier at the surface of cholesterol ester containing lipid droplets. Upon activation of PKA both HSL and Plin 1 undergo phosphorylation, the phosphorylated HSL docks to the Plin 1 and gains access to cholesterol esters (Fig. 1). Presently no data are available whether OPA1 exists in the cytosol of adrenocortical cells and whether, functioning as an AKAP, it enhances cAMPinduced aldosterone secretion.

When the cells are stimulated with a cAMP-mediated agonist, PKA may enhance cholesterol supply of mitochondria primarily by inducing and phosphorylating the cholesterol transporter StAR and the translocator protein TSPO (Holysz et al., 2011; Midzak et al., 2011). It may be assumed that without simulatenous activation of HSL StAR would function without substrate saturation. In fact, PKA phosphorylates also HSL (Hirsch and Rosen, 1984). Therefore HSL action on cytosolic cholesterol esters imported from the extracellular fluid as well as on those stored in lipid droplets (Hattangady et al., 2011; Rone et al., 2009; Vinson et al., 1992) may optimize cholesterol supply of mitochondria. Moreover, provided data can be extrapolated from adipocytes (Miyoshi et al., 2006), PKA phosphorylates perilipin and thereby facilitates the access of activated HSL to its substrate. If OPA1 is present in the extramitochondrial space, due to its AKAP domain it could enhance most or all of these processes. Moreover, even if HSL activity does not limit hormone production, induction and activation of StAR is CAMP PKA dependent, therefore the elimination of the AKAP function could still be reflected by attenuated cAMP - induced aldosterone production.

As a first approach to detect emOPA1 we applied immunocytochemical technique, using laser scanning confocal microscopy. In the first series OPA1 was immunolabeled and mitochondria were identified with mitochondrially targeted eGFP. In two further series immunostaining was applied to OPA1 as well as to cytochrome $c$, a mitochondrial marker located in the IMS whereas the lipid droplets were stained with the cholesterol ester analogue ChoIEsteryl-BODIPY. The overwhelming majority of OPA1 positive spots around the droplets colocalized with mitochondria. A few emOPA1 immunopositive spots could also be found, mostly but not exclusively in the vicinity of lipid droplets. Overall, nearly 40 per cent of cells displayed emOPA1 immunopositivity but the density of such signals was almost negligible. Therefore in spite of its presence in the extramitochondrial space it was dubious whether at such a low density in this space OPA1 can influence cholesterol and thereby steroid metabolism.

Cell fractionation studies yielded similar results. Three fractions were analyzed by means of Western blotting, the mitochondrial and cytosolic fractions as well as the uppermost layer of the cytosolic fraction, termed fat cake. This latter fraction contained a floating cloudy aggregate, probably corresponding to the lipid droplet-rich fat cake in the cytosolic fraction of lipocytes (Greenberg et al., 1991). Mitochondrial contamination of the post-mitochondrial fractions was estimated on basis of their COX IV and cytochrome $c$ content, markers of IMM and IMS, respectively. The clear-cut increase of OPA1/COX IV ratio in the cytosolic and fat cake fractions indicated the presence of OPA1 in the extramitochondrial compartment. The negligible amount of COX IV argues against the

Table 1

Aldosterone production by OPA1 - silenced cells, related to that by cells transfected with control RNA or Mfn1 siRNA.

\begin{tabular}{lllr}
\hline Agonist & $2 \mathrm{~h}$ & \multicolumn{2}{c}{$24 \mathrm{~h}$} \\
\cline { 2 - 3 } & Control RNA & Mfn1 siRNA & Control RNA \\
\hline 0.05 mM db-cAMP & $1.400 \pm 0.138$ & $1.340 \pm 0.131$ & $1.367 \pm 0.072$ \\
0.5 mM db-cAMP & $1.580 \pm 0.150$ & $1.450 \pm 0.114$ & $1.356 \pm 0.076$ \\
$1 \mathrm{nM}$ angiotensin II & $1.555 \pm 0.128$ & $1.514 \pm 0.094$ & $1.289 \pm 0.012$ \\
$10 \mathrm{nM}$ angiotensin II & & & $1.292 \pm 0.063$ \\
\hline
\end{tabular}


ssumption that mitochondrial contamination is a major factor accounting for the presence of OPA1 in the post-mitochondrial fractions. Unexpectedly, the pattern of OPA1 isoforms in the mitochondrial fraction differed from that in the post-mitochondrial fractions, being relatively enriched in short isoforms in the latter ones. Since long isoforms are strongly attached to the IMM by their transmembrane domain whereas the short isoforms, lacking transmembrane domain 1 (Song JCB 2007) are only weakly attached to membranes (Satoh et al., 2003), the damage of the OMM may lead to the leakage of short isoforms only. (Note that only a small fraction of cytochrome $c$ is bound to membranes (Cortese et al., 1998), therefore its leakage may exceed that of short OPA1 isoforms.) The presence of cytochrome $c$ in the cytosol supports the assumption that OMM damage of variable extent may have occurred during cell homogenization.

Since immunocytochemical and cell fractionation studies failed to provide unambiguous indication for the significance of emOPA1 we examined the effect of OPA1 siRNA on three PKA targets, namely HSL, the cAMP-evoked $\mathrm{Ca}^{2+}$ signaling and aldosterone production.

Two-hour stimulation with db-cAMP significantly enhanced the phosphorylation of HSL. Transfection with OPA1 siRNA was followed by a slight, statistically insignificant decrease in the mean value of phosphorylation. Angiotensin II-induced phosphorylation of HSL, accounted for by $\mathrm{Ca}^{2+}$ dependent activation of CaMKII (Cherradi et al., 1998) was not sensitive to OPA1 siRNA.

ACTH as well as 8-bromo-cAMP induce sustained $\mathrm{Ca}^{2+}$ response after a lag-time of a few minutes in rat (Tremblay et al., 1991) and human glomerulosa cells (Gallo-Payet et al., 1996). Similarly to myocardiac cells (Sperelakis and Schneider, 1976) this effect of cAMP in glomerulosa cells is brought about by the phosphorylation of L-type $\mathrm{Ca}^{2+}$ channels by PKA (Durroux et al., 1991). It follows that cAMP-induced $\mathrm{Ca}^{2+}$ signal could be regarded as an indicator of OPA1 functioning as an extramitochondrial AKAP. db-cAMP-induced $\mathrm{Ca}^{2+}$ signal in small fraction of the cells only. The signal developed after a lag-time of several minutes and in quite a few cases it was not substantial enough for reliable measurement. For these reasons the effect of OPA1 silencing on the effect of $0.05 \mathrm{mM}$ db-cAMP could not be conclusively evaluated. At a higher concentration $(0.5 \mathrm{mM})$ of the agonist, one third of the cells displayed $\mathrm{Ca}^{2+}$ signal and it was resistent to silencing of OPA1.

Irrespective of any effect of OPA1 on HSL in c-AMP acivated cells, its presumed action on PKA should facilitate phosphorylation and induction of StAR that in turn should lead to increased steroid production. Moreover, the biological significance of OPA1 in H295R cells depends should be indicated on by its effect on aldosterone secretion. Although aldosterone is one of several steroids produced by H295R cells, all these steroids derive from the same cholesterol pool and therefore aldosterone can be regarded as an appropriate indicator of mitochondrial access to cholesterol. At designing the experiments it had to be recalled that siRNA for OPA1 evokes fragmentation of mitochondria. In H295R cells the mitochondrion fragmenting effect of Mfn1 siRNA is comparable with that of OPA1 siRNA (Fülöp et al., 2011), therefore cells transfected with siRNA against Mfn1 were considered the appropriate control.

In principle, silencing of OPA1 might exert a dual action on aldosterone production, depending on the mode of action (cAMP or $\mathrm{Ca}^{2+}$ ) of the physiological agonist. Although angiotensin II is a $\mathrm{Ca}^{2+}$ mobilizing agonist and the action of ACTH is mediated by cAMP, there is some overlap between their mode of action. Angiotensin II, acting via the heterotrimeric G-protein $\mathrm{G}_{\mathrm{q}}$ (Gutowski et al., 1991), induces acute aldosterone secretion by $\mathrm{IP}_{3}$-mediated $\mathrm{Ca}^{2+}$ release (Enyedi et al., 1985), followed by $\mathrm{Ca}^{2+}$ influx (Hunyady et al., 1994; Kramer, 1988). The ensuing $\mathrm{Ca}^{2+}$ signal is a prerequisite for increased aldosterone secretion (Spät and Hunyady, 2004). ACTH or cAMP may also induce $\mathrm{Ca}^{2+}$ influx and this $\mathrm{Ca}^{2+}$ influx contributes to the stimulation of aldosterone (Balla et al. 1982). $\mathrm{Ca}^{2+}$ influx may be attributed to PKA-enhanced activation of L-type $\mathrm{Ca}^{2+}$ channels (Gallo-Payet et al., 1996; Lenglet et al., 2002). db-cAMP-induced $\mathrm{Ca}^{2+}$ signals were observed also in the present experiments. It follows that $\mathrm{Ca}^{2+}$ signaling may be a common element in the action of angiotensin II and cAMP. In contrast to $\mathrm{Ca}^{2+}$ signaling, cAMP is not a common mediator of the two agonists. In addition to $G_{q}$ angiotensin II also activates the adenylyl cyclase inhibitory $G$ protein $G_{i}$ (Enyedi et al., 1986; Maturana et al., 1999). This may be the reason why the peptide does not increase the generation of cAMP (Bell et al., 1981; Hausdorff et al., 1987) despite the probable expression (Tait and Tait, 1999) of $\mathrm{Ca}^{2+}$ sensitive isoforms of adenylyl cyclase (Hanoune and Defer, 2001).

Cytosolic $\mathrm{Ca}^{2+}$ signal is transferred into the mitochondrial matrix (Hajnóczky et al., 1995; Pralong et al., 1992; Rizzuto et al., $1992)$ and the elevated mitochondrial $\left[\mathrm{Ca}^{2+}\right]$ contributes to the enhancement of steroid production (Spät et al., 2012; Wiederkehr et al., 2011). Therefore changes in mitochondrial $\mathrm{Ca}^{2+}$ metabolism should be considered at evaluating the effect of OPA1 knockdown on aldosterone production. Applying the mitochondrially targeted $\mathrm{Ca}^{2+}$-sensitive proteins $4 \mathrm{mt}-\mathrm{D} 2$ and mt-inverse Pericam we observed that knockdown of OPA1 significantly enhanced mitochondrial $\mathrm{Ca}^{2+}$ uptake both in intact and permeabilized H295R and HeLa cells (Fülöp et al., 2011). This enhancement was associated with increased aldosterone production (Spät et al., 2012). Our data on HeLa cells have not been confirmed by Kushnareva et al. (2012) who estimated $\left[\mathrm{Ca}^{2+}\right]_{\mathrm{m}}$ with Rhod-2, a dye less specific for mitochondria than the mitochondrially targeted proteins applied in our experiments. Alluding to the increased circularity (a parameter indicating fragmentation) of mitochondria in the OPA1-silenced cells (Fülöp et al., 2011) Kushnareva et al. attributed our results to swelling of mitochondria. It should, however, be recalled that we observed enhanced $\mathrm{Ca}^{2+}$ uptake also in comparison with $M f n 1-s i l e n c e d$ cells, displaying circularity identical with that in OPA1-silenced cells. Kushnareva et al. also reported that the number of $\mathrm{Ca}^{2+}$ pulses required to activate mitochondrial permeability transition pore is less in OPA1-silenced cells than in sham-transfected controls. This observation may indicate enhanced rather than attenuated $\mathrm{Ca}^{2+}$ uptake (cf. e.g. (Joiner et al., 2012; Mallilankaraman et al., 2012)). In addition to increased mitochondrial $\mathrm{Ca}^{2+}$ uptake knock-down of OPA1 may enhance aldosterone production also by enhanced cholesterol transport through the IMM into the matrix, as observed in trophoblast cells (Wasilewski et al., 2012).

Again, in contrast to $\mathrm{Ca}^{2+}$ signaling, cAMP is not a common intracellular mediator of ACTH and AII. Therefore, in OPA1-silenced cells, due to the elimination of the presumed AKAP function, the amplification of secretory response to db-cAMP should be smaller than in angiotensin II-stimulated cell. Nevertheless, this was not the case. In fact, silencing of OPA1 the fold-response to all the stimuli increased in each group to the same extent, irrespective whether PKA participated in the activation of steroid production. This indicates that AKAP action of OPA1 has no role in the activation of CAMP-PKA mediated hormone production.

A special member of the AKAP family, AKAP121 can be anchored to mitochondria and may compartmentalize PKA as well as other proteins on the OMM (Wong and Scott, 2004). In Leydig cells, cAMP-induced StAR expression and steroidogenesis were found to correlate with the extent of AKAP 121 expression (Dyson et al., 2008). Expression and role of AKAP121 in H295R cells deserve elucidation.

In a recent review on OPA1 Belenguer and Pellegrini (Belenguer and Pellegrini, 2012) emphasized the possibility that OPA1 reported to be present in the lipid droplet fraction of adipocytes (Pidoux et al., 2011) may have been due to contamination with mitochondria. These authors raised several questions concerning the proposed role of OPA1 in lipolysis. Our observations support 
the presence of OPA 1 in the extramitochondrial space, for the first time in a cell type other than adipocyte. At the same time we obtained no evidence for the role of this fraction of OPA1 in CAMPmediated steroid hormone production, the specific biological function of adrenocortical cells.

\section{Acknowledgements}

This work was supported by the Hungarian Council for Medical Research (ETT 008-09). The excellent technical assistance of Ms. Eszter Halász is highly appreciated.

\section{Appendix A. Supplementary material}

Supplementary data associated with this article can be found, in the online version, at http://dx.doi.org/10.1016/j.mce.2013.07.021.

\section{References}

Arnoult, D., Grodet, A., Lee, Y.J., Estaquier, J., Blackstone, C., 2005. Release of OPA1 during apoptosis participates in the rapid and complete release of cytochrome c and subsequent mitochondrial fragmentation. J. Biol. Chem. 280, 35742-35750.

Balla, T., Hunyady, L., Spät, A., 1982. Possible role of calcium uptake and calmodulin in adrenal glomerulosa cells: effects of verapamil and trifluoperazine. Biochem. Pharmacol. 31, 1267-1271.

Belenguer, P., Pellegrini, L., 2012. The dynamin GTPase OPA1: more than mitochondria? Biochim. Biophys. Acta 1833, 176-183.

Bell, J.B.G., Tait, J.F., Tait, S.A.S., Barnes, G.D., Brown, B.L., 1981. Lack of effect of angiotensin on levels of cyclic AMP in isolated adrenal zona glomerulosa cells from the rat. J. Endocrinol. 91, 145-154.

Betancourt-Calle, S., Calle, R.A., Isales, C.M., White, S., Rasmussen, H., Bollag, W.B., 2001. Differential effects of agonists of aldosterone secretion on steroidogenic acute regulatory phosphorylation. Mol. Cell. Endocrinol. 173, 87-94.

Brasaemle, D.L., Subramanian, V., Garcia, A., Marcinkiewicz, A., Rothenberg, A., 2009. Perilipin A and the control of triacylglycerol metabolism. Mol. Cell Biochem. 326, 15-21.

Cherradi, N., Brandenburger, Y., Capponi, A.M., 1998. Mitochondrial regulation of mineralocorticoid biosynthesis by calcium and the StAR protein. Eur. J. Endocrinol. 139, 249-256.

Cherradi, N., Pardo, B., Greenberg, A.S., Kraemer, F.B., Capponi, A.M., 2003. Angiotensin II activates cholesterol ester hydrolase in bovine adrenal glomerulosa cells through phosphorylation mediated by p42/p44 mitogenactivated protein kinase. Endocrinology 144, 4905-4915.

Cipolat, S., Martins, d.B., Dal Zilio, B., Scorrano, L., 2004. OPA1 requires mitofusin 1 to promote mitochondrial fusion. Proc. Natl. Acad. Sci. USA 101, 15927-15932.

Clark, B.J., Pezzi, V., Stocco, D.M., Rainey, W.E., 1995. The steroidogenic acute regulatory protein is induced by angiotensin II and $\mathrm{K}^{+}$in $\mathrm{H} 295 \mathrm{R}$ adrenocortical cells. Mol. Cell. Endocrinol. 115, 215-219.

Cortese, J.D., Voglino, A.L., Hackenbrock, C.R., 1998. Multiple conformations of physiological membrane-bound cytochrome $c$. Biochemistry 37, 6402-6409.

Coulombe, N., Lefebvre, A., Lehoux, J.G., 1996. Characterization of the hamster CYP11B2 gene regulatory regions. Endocr. Res. 22, 653-661.

Delettre, C., Lenaers, G., Griffoin, J.M., Gigarel, N., Lorenzo, C., Belenguer, P., Pelloquin, L., Grosgeorge, J., Turc-Carel, C., Perret, E., Astarie-Dequeker, C., Lasquellec, L., Arnaud, B., Ducommun, B., Kaplan, J., Hamel, C.P., 2000. Nuclear gene OPA1, encoding a mitochondrial dynamin-related protein, is mutated in dominant optic atrophy. Nat. Genet. 26, 207-210.

Durroux, T., Gallo-Payet, N., Payet, M.D., 1991. Effects of adrenocorticotropin on action potential and calcium currents in cultured rat and bovine glomerulosa cells. Endocrinology 129, 2139-2147.

Dyson, M.T., Jones, J.K., Kowalewski, M.P., Manna, P.R., Alonso, M., Gottesman, M.E., Stocco, D.M., 2008. Mitochondrial A-kinase anchoring protein 121 binds type II protein kinase $A$ and enhances steroidogenic acute regulatory protein-mediated steroidogenesis in MA-10 mouse leydig tumor cells. Biol. Reprod. 78, 267-277.

Enyedi, P., Büki, B., Mucsi, I., Spät, A., 1985. Polyphosphoinositide metabolism in adrenal glomerulosa cells. Mol. Cell. Endocrinol. 41, 105-112.

Enyedi, P., Mucsi, I., Hunyady, L., Catt, K.J., Spät, A., 1986. The role of guanyl nucleotide binding proteins in the formation of inositol phosphates in adrenal glomerulosa cells. Biochem. Biophys. Res. Commun. 140, 941-947.

Eura, Y., Ishihara, N., Yokota, S., Mihara, K., 2003. Two mitofusin proteins, mammalian homologues of FZO, with distinct functions are both required for mitochondrial fusion. J. Biochem. 134, 333-344.

Fleury, A., Mathieu, A.P., Ducharme, L., Hales, D.B., Lehoux, J.G., 2004. Phosphorylation and function of the hamster adrenal steroidogenic acute regulatory protein (StAR). J. Steroid Biochem. Mol. Biol. 91, 259-271.

Frey, T.G., Renken, C.W., Perkins, G.A., 2002. Insight into mitochondrial structure and function from electron tomography. Biochim. Biophys. Acta 1555, 196-203.

Fülöp, L., Szanda, G., Enyedi, B., Várnai, P., Spät, A., 2011. The effect of OPA1 on mitochondrial $\mathrm{Ca}^{2+}$ signaling. PLoS One 6, e25199.
Gallo-Payet, N., Grazzini, E., C“t, M., Chouinard, L., Chorvatova, A., Bilodeau, L., Payet, M.D., Guillon, G., 1996. Role of $\mathrm{Ca}^{2+}$ in the action of adrenocorticotropin in cultured human adrenal glomerulosa cells. J. Clin. Invest. 98, 460-466.

Granneman, J.G., Moore, H.P., 2008. Location, location: protein trafficking and lipolysis in adipocytes. Trends Endocrinol. Metab 19, 3-9.

Granneman, J.G., Moore, H.P., Mottillo, E.P., Zhu, Z., Zhou, L., 2011. Interactions of perilipin-5 (Plin5) with adipose triglyceride lipase. J. Biol. Chem. 286, 51265135.

Greenberg, A.S., Egan, J.J., Wek, S.A., Garty, N.B., Blanchette-Mackie, E.J., Londos, C., 1991. Perilipin, a major hormonally regulated adipocyte-specific phosphoprotein associated with the periphery of lipid storage droplets. J. Biol. Chem. 266, 11341-11346.

Greenberg, A.S., Kraemer, F.B., Soni, K.G., Jedrychowski, M.P., Yan, Q.W., Graham, C.E., Bowman, T.A., Mansur, A., 2011. Lipid droplet meets a mitochondrial protein to regulate adipocyte lipolysis. EMBO J. 30, 4337-4339.

Gutowski, S., Smrcka, A., Nowak, L., Wu, D., Simon, M., Sternweis, P.C., 1991. Antibodies to the alpha $\mathrm{q}_{\mathrm{q}}$ subfamily of guanine nucleotide-binding regulatory protein à subunits attenuate activation of phosphatidylinositol 4,5bisphosphate hydrolysis by hormones. J. Biol. Chem. 266, 20519-20524.

Hajnóczky, G., Robb-Gaspers, L.D., Seitz, M.B., Thomas, A.P., 1995. Decoding of cytosolic calcium oscillations in the mitochondria. Cell 82, 415-424.

Hanoune, J., Defer, N., 2001. Regulation and role of adenylyl cyclase isoforms. Annu. Rev. Pharmacol. Toxicol. 41, 145-174.

Hattangady, N.G., Olala, L.O., Bollag, W.B., Rainey, W.E., 2011. Acute and chronic regulation of aldosterone production. Mol. Cell Endocrinol.

Hausdorff, W.P., Sekura, R.D., Aguilera, G., Catt, K.J., 1987. Control of aldosterone production by angiotensin II is mediated by two guanine nucleotide regulatory proteins. Endocrinology 120, 1668-1678.

Hirsch, A.H., Rosen, O.M., 1984. Lipolytic stimulation modulates the subcellular distribution of hormone-sensitive lipase in 3T3-L1 cells. J. Lipid Res. 25, 665677.

Holm, C., Osterlund, T., Laurell, H., Contreras, J.A., 2000. Molecular mechanisms regulating hormone-sensitive lipase and lipolysis. Annu. Rev Nutr. 20, 365-393.

Holysz, M., Derebecka-Holysz, N., Trzeciak, W.H., 2011. Transcription of LIPE gene encoding hormone-sensitive lipase/cholesteryl esterase is regulated by SF-1 in human adrenocortical cells: involvement of protein kinase A signal transduction pathway. J. Mol. Endocrinol. 46, 29-36.

Hsieh, K., Lee, Y.K., Londos, C., Raaka, B.M., Dalen, K.T., Kimmel, A.R., 2012. Perilipin family members preferentially sequester to either triacylglycerol-specific or cholesteryl-ester-specific intracellular lipid storage droplets. J. Cell Sci. 125, 4067-4076.

Hunyady, L., Rohács, T., Bagó, A., Deák, Spät, A., 1994. Dihydropyridine-sensitive initial component of the ANG II- induced $\mathrm{Ca} 2+$ response in rat adrenal glomerulosa cells. Am. J. Physiol. Cell Physiol. 266, C67-C72.

Joiner, M.L., Koval, O.M., Li, J., He, B.J., Allamargot, C., Gao, Z., Luczak, E.D., Hall, D.D., Fink, B.D., Chen, B., Yang, J., Moore, S.A., Scholz, T.D., Strack, S., Mohler, P.J., Sivitz, W.I., Song, L.S., Anderson, M.E., 2012. CaMKII determines mitochondrial stress responses in heart. Nature 491, 269-273.

Kraemer, F.B., Shen, W.J., Harada, K., Patel, S., Osuga, J., Ishibashi, S., Azhar, S., 2004. Hormone-sensitive lipase is required for high-density lipoprotein cholesteryl ester-supported adrenal steroidogenesis. Mol Endocrinol 18, 549-557.

Kramer, R.E., 1988. Angiotensin II-stimulated changes in calcium metabolism in cultured glomerulosa cells. Mol. Cell. Endocrinol. 60, 199-210.

Kushnareva, Y.E., Gerencser, A.A., Bossy, B., Ju, W.K., White, A.D., Waggoner, J., Ellisman, M.H., Perkins, G., Bossy-Wetzel, E., 2012. Loss of OPA1 disturbs cellular calcium homeostasis and sensitizes for excitotoxicity. Cell Death Differ..

Lenaers, G., Reynier, P., Elachouri, G., Soukkarieh, C., Olichon, A., Belenguer, P., Baricault, L., Ducommun, B., Hamel, C., Delettre, C., 2009. OPA1 functions in mitochondria and dysfunctions in optic nerve. Int. J. Biochem. Cell Biol. 41, 1866-1874.

Lenglet, S., Louiset, E., Delarue, C., Vaudry, H., Contesse, V., 2002. Activation of 5$\mathrm{HT}(7)$ receptor in rat glomerulosa cells is associated with an increase in adenylyl cyclase activity and calcium influx through T-type calcium channels. Endocrinology 143, 1748-1760.

Liesa, M., Palacin, M., Zorzano, A., 2009. Mitochondrial dynamics in mammalian health and disease. Physiol. Rev. 89, 799-845.

Lucki, N.C., Bandyopadhyay, S., Wang, E., Merrill, A.H., Sewer, M.B., 2012. Acid ceramidase (ASAH1) is a global regulator of steroidogenic capacity and adrenocortical gene expression. Mol. Endocrinol. 26, 228-243.

Mallilankaraman, K., Doonan, P., Cardenas, C., Chandramoorthy, H.C., Muller, M., Miller, R., Hoffman, N.E., Gandhirajan, R.K., Molgo, J., Birnbaum, M.J., Rothberg, B.S., Mak, D.O., Foskett, J.K., Madesh, M., 2012. MICU1 Is an essential gatekeeper for MCU-mediated mitochondrial $\mathrm{Ca}(2+)$ uptake that regulates cell survival. Cell 151, 630-644.

Manna, P.R., Dyson, M.T., Eubank, D.W., Clark, B.J., Lalli, E., Sassone-Corsi, P., Zeleznik, A.J., Stocco, D.M., 2002. Regulation of steroidogenesis and the steroidogenic acute regulatory protein by a member of the cAMP responseelement binding protein family. Mol. Endocrinol. 16, 184-199.

Martin, L.J., Boucher, N., Brousseau, C., Tremblay, J.J., 2008. The orphan nuclear receptor NUR77 regulates hormone-induced StAR transcription in Leydig cells through cooperation with Ca2+/calmodulin-dependent protein kinase I. Mol. Endocrinol. 22, 2021-2037.

Maturana, A.D., Casal, A.J., Demaurex, N., Vallotton, M.B., Capponi, A.M., Rossier, M.F., 1999. Angiotensin II negatively modulates L-type calcium channels through a pertussis toxin-sensitive $G$ protein in adrenal glomerulosa cells. J. Biol. Chem. 274, 19943-19948. 
Midzak, A., Rone, M., Aghazadeh, Y., Culty, M., Papadopoulos, V., 2011. Mitochondrial protein import and the genesis of steroidogenic mitochondria. Mol. Cell Endocrinol. 336, 70-79.

Miyoshi, H., Souza, S.C., Zhang, H.H., Strissel, K.J., Christoffolete, M.A., Kovsan, J., Rudich, A., Kraemer, F.B., Bianco, A.C., Obin, M.S., Greenberg, A.S., 2006. Perilipin promotes hormone-sensitive lipase-mediated adipocyte lipolysis via phosphorylation-dependent and -independent mechanisms. J. Biol. Chem. 281, 15837-15844.

Olichon, A., Baricault, L., Gas, N., Guillou, E., Valette, A., Belenguer, P., Lenaers, G., 2003. Loss of OPA 1 perturbates the mitochondrial inner membrane structure and integrity, leading to cytochrome c release and apoptosis. J. Biol. Chem. 278, 7743-7746.

Pidoux, G., Witczak, O., Jarnaess, E., Myrvold, L., Urlaub, H., Stokka, A.J., Kuntziger, T., Tasken, K., 2011. Optic atrophy 1 is an A-kinase anchoring protein on lipid droplets that mediates adrenergic control of lipolysis. EMBO J. 30, 4371-4386.

Pralong, W.F., Hunyady, L., Várnai, P., Wollheim, C.B., Spät, A., 1992. Pyridine nucleotide redox state parallels production of aldosterone in potassiumstimulated adrenal glomerulosa cells. Proc. Natl. Acad. Sci. USA 89, 132-136.

Rizzuto, R., Simpson, A.W.M., Brini, M., Pozzan, T., 1992. Rapid changes of mitochondrial $\mathrm{Ca}^{2+}$ revealed by specifically targeted recombinant aequorin. Nature 358, 325-327.

Rodrigueza, W.V., Thuahnai, S.T., Temel, R.E., Lund-Katz, S., Phillips, M.C., Williams, D.L., 1999. Mechanism of scavenger receptor class B type I-mediated selective uptake of cholesteryl esters from high density lipoprotein to adrenal cells. J. Biol. Chem. 274, 20344-20350.

Rone, M.B., Fan, J., Papadopoulos, V., 2009. Cholesterol transport in steroid biosynthesis: role of protein-protein interactions and implications in disease states. Biochim. Biophys. Acta 179, 646-658.

Satoh, M., Hamamoto, T., Seo, N., Kagawa, Y., Endo, H., 2003. Differential sublocalization of the dynamin-related protein OPA1 isoforms in mitochondria. Biochem. Biophys. Res. Commun. 300, 482-493.

Scorrano, L., Ashiya, M., Buttle, K., Weiler, S., Oakes, S.A., Mannella, C.A., Korsmeyer, S.J., 2002. A distinct pathway remodels mitochondrial cristae and mobilizes cytochrome c during apoptosis. Dev. Cell 2, 55-67.

Servetnick, D.A., Brasaemle, D.L., Gruia-Gray, J., Kimmel, A.R., Wolff, J., Londos, C., 1995. Perilipins are associated with cholesteryl ester droplets in steroidogenic adrenal cortical and Leydig cells. J. Biol. Chem. 270, 16970-16973.

Spät, A., Fülöp, L., Szanda, G., 2012. The role of mitochondrial $\mathrm{Ca}(2+)$ and $\mathrm{NAD}(\mathrm{P}) \mathrm{H}$ in the control of aldosterone secretion. Cell Calcium 52, 64-72.

Spät, A., Hunyady, L., 2004. Control of aldosterone secretion: a model for convergence in cellular signaling pathways. Physiol. Rev. 84, 489-539.

Sperelakis, N., Schneider, J.A., 1976. A metabolic control mechanism for calcium ion influx that may protect the ventricular myocardial cell. Am. J. Cardiol. 37, 1079-1085.
Subramanian, V., Rothenberg, A., Gomez, C., Cohen, A.W., Garcia, A., Bhattacharyya, S., Shapiro, L., Dolios, G., Wang, R., Lisanti, M.P., Brasaemle, D.L., 2004. Perilipin A mediates the reversible binding of CGI-58 to lipid droplets in 3T3-L1 adipocytes. J. Biol. Chem. 279, 42062-42071.

Sukhorukov, V.M., Bereiter-Hahn, J., 2009. Anomalous diffusion induced by cristae geometry in the inner mitochondrial membrane. PLoS One 4, e4604.

Sztalryd, C., Xu, G., Dorward, H., Tansey, J.T., Contreras, J.A., Kimmel, A.R., Londos, C., 2003. Perilipin A is essential for the translocation of hormone-sensitive lipase during lipolytic activation. J Cell Biol 161, 1093-1103.

Tait, J.F., Tait, S.A.S., 1999. Role of cAMP in the effects of $\mathrm{K}^{+}$on the steroidogenesis of zona glomerulosa cells. Clin. Exp. Pharmacol. Physiol. 26, 947-955.

Tansey, J.T., Sztalryd, C., Gruia-Gray, J., Roush, D.L., Zee, J.V., Gavrilova, O., Reitman, M.L., Deng, C.X., Li, C., Kimmel, A.R., Londos, C., 2001. Perilipin ablation results in a lean mouse with aberrant adipocyte lipolysis, enhanced leptin production, and resistance to diet-induced obesity. Proc. Natl. Acad. Sci USA 98, 6494-6499.

Tremblay, E., Payet, M.D., Gallo-Payet, N., 1991. Effects of ACTH and angiotensin Il on cytosolic calcium in cultured adrenal glomerulosa cells. Role of cAMP production in the ACTH effect. Cell Calcium 12, 655-673.

Trzeciak, W.H., Boyd, G.S., 1974. Activation of cholesteryl esterase in bovine adrenal cortex. Eur. J. Biochem. 46, 201-207.

Vinson, G.P., Whitehouse, B., Hinson, J., 1992. The Adrenal Cortex. Prentice Hall Englewood Cliffs, NJ, 07632.

Wasilewski, M., Semenzato, M., Rafelski, S.M., Robbins, J., Bakardjiev, A.I., Scorrano L., 2012. Optic atrophy 1-dependent mitochondrial remodeling controls steroidogenesis in trophoblasts. Curr. Biol. 22, 1228-1234.

Wiederkehr, A., Szanda, G., Akhmedov, D., Mataki, C., Heizmann, C.W., Schoonjans, K., Pozzan, T., Spät, A., Wollheim, C.B., 2011. Mitochondrial matrix calcium is an activating signal for hormone secretion. Cell Metab. 13, 601-611.

Wong, W., Scott, J.D., 2004. AKAP signalling complexes: focal points in space and time. Nat. Rev. Mol. Cell Biol. 5, 959-970.

Yamaguchi, T., Omatsu, N., Morimoto, E., Nakashima, H., Ueno, K., Tanaka, T. Satouchi, K., Hirose, F., Osumi, T., 2007. CGI-58 facilitates lipolysis on lipid droplets but is not involved in the vesiculation of lipid droplets caused by hormonal stimulation. J. Lipid Res. 48, 1078-1089.

Zhang, H.H., Souza, S.C., Muliro, K.V., Kraemer, F.B., Obin, M.S., Greenberg, A.S., 2003. Lipase-selective functional domains of perilipin A differentially regulate constitutive and protein kinase A-stimulated lipolysis. J. Biol. Chem. 278, 51535-51542.

Zimmermann, R., Strauss, J.G., Haemmerle, G., Schoiswohl, G., Birner-Gruenberger R., Riederer, M., Lass, A., Neuberger, G., Eisenhaber, F., Hermetter, A., Zechner, R. 2004. Fat mobilization in adipose tissue is promoted by adipose triglyceride lipase. Science 306, 1383-1386. 